\title{
Probabilistic Evaluation of Reserve ReQuirements of Generating Systems with Renewable Power Sources: The Portuguese and Spanish Cases
}

\author{
Manuel Matos ${ }^{1}$ João Peças Lopes ${ }^{1}$ Mauro Rosa $^{1}$ Ricardo Ferreira ${ }^{1}$ \\ Armando Leite da Silva $^{2}$ Warlley Sales ${ }^{2}$ Leonidas Resende ${ }^{2}$ Luiz Manso ${ }^{2}$ \\ Pedro Cabral ${ }^{3}$ Marco Ferreira ${ }^{3}$ Nuno Martins ${ }^{3}$ Carlos Artaiz $^{4}$ Fernando Soto ${ }^{4}$ Rubén López ${ }^{4}$ \\ ${ }^{1}$ INESC Porto, FEUP, Portugal, $\quad{ }^{2}$ Federal University of Itajubá - UNIFEI, Brazil, \\ ${ }^{3}$ Rede Eléctrica Nacional - REN, Portugal, ${ }^{4}$ Red Eléctrica de España - REE, Spain.
}

\begin{abstract}
This paper presents an application of probabilistic methodologies to evaluate the reserve requirements of generating systems with large amounts of renewable energy sources. The idea is to investigate the behavior of reliability indices, including those from the well-being analysis, when the major portion of the renewable sources comes from the wind power. Renewable in this work mainly comprises hydroelectric, minihydroelectric and wind power sources. Case studies on configurations of the Portuguese and Spanish generating systems are presented and discussed.
\end{abstract}

Index Terms: Power system reliability, Generating system adequacy, Operating reserve, Monte Carlo simulation, Renewable energy sources.

\section{INTRODUCTION}

$\mathrm{T}$ HE increased use of electricity produced from renewable energy sources constitutes an important part of the package of measures needed to comply with the Kyoto Protocol to the United Nations Framework Convention on Climate Change. Renewable energy source is defined as any energy resource naturally regenerated over a short time scale that is derived directly from the sun (such as solar thermal and photovoltaic), indirectly from the sun (such as wind, hydropower and photosynthetic energy stored in biomass), or from other natural movements and mechanisms of the environment (such as geothermal and ocean energy) [1]. Renewable energies can play a major role in tackling the twin challenge of energy security and global warming because they are not depletable and produce less greenhouse-gas emissions than fossil fuels. The promotion of this type of electricity has a high priority in many countries, in particular, in the European Union.

In the last few years, several discussions among European governments and associations have been carried, and in March 2007, Europe's Heads of States agreed to a binding target of $20 \%$ renewable energy by 2020 [2], [3]. This decision gives a strong signal for Europe's future energy policy as well as for the further expansion of the European renewable energy industry, which includes the development of new ways of operating and planning power systems.

While contributions from renewable energy sources for electricity production is small, with the exception of hydro, their market penetration is growing at a much faster rate than any other conventional source. Although there are still many potential hydro sites in the world, severe restriction based mainly on environmental aspects have limited their exploitation.

Wind has become a popular source of green electricity around the world [4]. At the end of 2005, the worldwide capacity of wind-powered generators was 59 GW; in Spain, about 10GW of installed capacity has produced more than $8 \%$ of its total energy needs, and in Portugal, about $1 \mathrm{GW}$ of installed capacity has produced almost $4 \%$ of its needs. At the end of 2006, the global capacity of wind-powered generators reached almost 74GW; Spain and Portugal have the second and nineth largest installed capacity in the world.

The previous values put system operators and planners under a huge pressure to come up with solutions bearing in mind these new technologies. The main reason is that the number of random variables and system complexities greatly increase, when renewable energy sources are added to the system, due to the fluctuating capacity levels of these sources. New computational models and tools have to be developed to deal with these new variables, particularly those related with wind power. A huge number of technical works have recently been published in this area: see, for instance [5]-[12].

From the planning point of view, deterministic based approaches have very attractive characteristics such as simple implementation, easy understanding, assessment and judgment by planners in relation to severe conditions like network outages and system peak load. Unfortunately, the perception of many planning engineers that past experience in addition to some known critical situations is enough to assess system risk conditions is not valid. In addition, past experience with renewable sources like wind power is very limited. However, the principles of some deterministic standards (e.g. "N-1" criterion) must be recognized as attractive.

Conversely, methodologies based on probability concepts can be extremely useful in assessing the performance of power systems [13]. They have been successfully applied to many areas including generation and transmission capacity planning, operating reserve assessment, distribution systems, etc. The proper measure of risk can only be achieved by recognizing the probabilistic nature of power system parameters. 
A new framework, named system well-being analysis [14]-[16], has been built combining the deterministic perception with probability concepts. This new framework reduces the gap between deterministic and probabilistic approaches by providing the ability to measure the degree of success of any operating system state. In a well-being analysis, success states are further split into healthy and marginal states, using the previously mentioned engineers' perception as the criterion. Well-being analysis has been applied in the last decade to areas such as generating systems, operating reserve assessment, and composite generation and transmission systems. Chronological or sequential Monte Carlo simulation has been used for generating system well-being analysis, considering the loss of the largest available unit in the system as the deterministic criterion. These concepts can be extremely useful for dimensioning the reserve capacities considering renewable resources [17]-[24].

This paper presents an application of chronological Monte Carlo simulation (MCS) to evaluate the reserve requirements of generating systems, considering renewable energy sources. The idea is to study the behavior of reliability indices (conventional and wellbeing), when a major portion of the energy sources is renewable. Renewable comprises mainly hydro, wind, mini-hydro power sources, although other sources such as solar are present in much lesser amounts.

Case studies with the Portuguese and Spanish generating systems are presented and discussed. The work was developed in the framework of a RTD project financed by the TSO of Portugal and Spain (REN and REE, respectively) within their activities related to MIBEL (the Iberian electricity market), with the aim of maximizing the integration of renewable energy.

\section{Proposed Methodology}

The estimates of reliability indices are based on two distinct representations: state space and chronological modeling. State enumeration and non-sequential MCS methods are examples of state space based algorithms, where Markov models are usually used for both equipment and load state transitions. Therefore, states are selected and evaluated without considering any time connection. Conversely, sequential simulation can perceive all chronological aspects and, hence, it is able to correctly represent equipment aging process, time varying loads, spatial and time correlation aspects, etc. Chronological modeling, however, implies that two consecutive state samples differ from each other on only one state component and so, it requires considerably more computational effort. A method named pseudochronological MCS has also been proposed [25], which preserves the efficiency of the non-sequential MCS and the modeling ability of the chronological simulation.

Chronological MCS is very suitable due to its flexibility, as it allows the representation of non-exponential residence times, useful when dealing with chronological processes. Moreover, as dealing with renewable energy sources and their natural uncertainties, due to hydrologic inflow sequences, wind speed variations etc., chronological MCS seems to be the most effective way to adequately model and solve these difficulties.

\section{A. Chronological Monte Carlo Simulation}

The operation history of system states, for a simulation period $\mathrm{T}$, is based on stochastic models of the components and on the load model. The initial operating state is sampled from the probability distributions of the generating equipment. After evaluating each state, performance indices are estimated using test-functions $\mathrm{G}(\mathrm{t})$ :

$$
E(G)=\frac{1}{T} \int_{0}^{T} G(t) d t .
$$

Each performance index can be estimated using a suitable test-function. The failure probability, for instance, corresponds to the expected value of an indicator function where $G(t)=1$ if the system associated with time $t$ is a failure state; otherwise $G(t)=0$. Another way of estimating the expected value of $G(t)$ is shown as follows:

$$
\tilde{E}(G)=\frac{1}{N Y} \sum_{k=1}^{N Y} G\left(y_{k}\right)
$$

where NY is the no. of simulated years and $y_{k}$ is a sequence of system states in year k. For instance, the energy not supplied will be the summation of unsupplied energy associated with each interruption of a simulated year. The uncertainty around the estimated indices is given by the variance of the estimator:

$$
V(\tilde{E}(G))=\frac{V(G)}{N Y}
$$

where $V(G)$ is the variance of the test-function. The convergence of the simulation process is tested using the coefficient of variation $\beta$ [25].

$$
\beta=\sqrt{V(\tilde{E}[G])} / \tilde{E}[G] .
$$

\section{1) Modeling of Thermal Units}

A two-state Markov model is used for modeling the up/down cycle of all thermal generating units. They are specified through their failure $(\lambda)$ and repair $(\mu)$ rates. Clearly, any non-Markovian model could be used if the necessary parameters are available. Fig. 1a shows the well known two-state Markov model [13]. The generating capacity of the thermal units are fixed and pre-specified.

\section{2) Modeling of Hydroelectric Units}

The capacities of the hydro units will be defined for each month, according to the corresponding hydrological series. These series are defined for each 
hydraulic basin based on historical data and aim at capturing the historical inflows, reservoir volumes and type of operation. Mathematical polynomials convert the monthly storage volume of each reservoir into available power capacity for the month. In the case of hydro power plants with pumping capacity, some additional evaluations are carried out. Historical yearly series of volumes per power plant and per month have to be provided.

\section{3) Modeling of Wind Units}

Usually, in a wind power site, there are several generating units and they will be grouped into an equivalent multi-state Markov model, as shown in Fig. 1b. Only two stochastic parameters are necessary: unit failure and repair rates. Parameter $N$ represents the number of generating units of the wind farm. If $C$ is the unit capacity, the amount of power associated with the $k^{\text {th }}$ state is given by $C_{k}=(N-k) \times C, k=0, \ldots, N$. The cumulative probability $P_{k}$ (from 0 to $k$ ) associated with this state can be easily calculated. In order to reduce the number of these states during the chronological MCS, a simple truncation process sets the desired order of accuracy. Therefore, instead of $N+1$ states, a much smaller number up to the capacity $C_{L}$ will limit this model; e.g. 1- $P_{L} \leq$ tolerance.

The productions of the wind generating units will be defined for each hour, according to the hourly wind series for each geographic region. The wind series try to capture the wind speed and power conversion characteristics. Historical yearly series of per unit capacity fluctuations per hour have to be provided.

\section{4) Modeling of Mini-Hydro}

Mini-hydro units are modeled similarly to the hydro generating units from the hydrological point of view, but they are grouped into multi-state units of Fig. 1b to simplify the modeling processing. Due to the lack of specific data in relation to the hydrological basin where they are located, an equivalent reservoir is used to model the capacity variations with time. Obviously, if specific data are available, they can be properly considered.

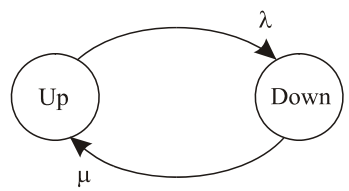

(a)

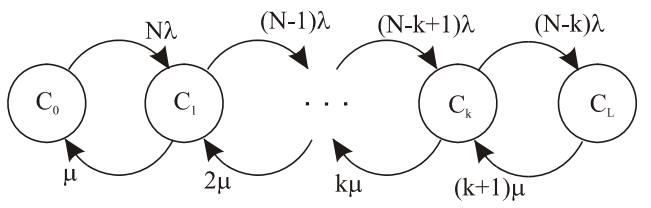

(b)

Figure 1: (a) Two-state; (b) Multi-states Markov models.
One has always to balance the benefits in terms of accuracy and the cost in terms of computing effort and levels of model detail.

\section{5) Modeling of Co-Generation}

Co-generating units are modeled similarly to the thermal units, but like in the previous case, they are clustered as well by using multi-state units of Fig. 1b.

Moreover an hourly utilization factor is specified, which models the actual co-generation power used by the system. This factor varies during the year following the tariff attractiveness and/or the industry production cycle

\section{6) Maintenance Aspects}

A certain amount of power generation will be specified per month in order to capture the maintenance activities along the year. In order to deal with that, the proposed chronological MCS algorithm, according to the generating power on maintenance, adequately increases the hourly load curve. This simplified model is particularly useful for planning purposes, since it is difficult to accurately specify the exact period for generating unit maintenance activities. For some nuclear power generators, due to its peculiarities, it is possible to detail this period and the chronological simulation should account for that.

\section{7) Load Characteristics}

A standard chronological load model containing 8760 levels, corresponding to each hour, is used. The chronological MCS will sequentially follow these load steps during the simulation process. Two uncertainty levels, representing short and long-term load forecasting deviations can be simulated through the MCS process. Gaussian or any other distribution can be used.

\section{B. Conventional Reliability Indices}

The conventional reliability indices are: LOLP = loss of load probability; LOLE = loss of load expectation; EPNS = expected power not supplied; EENS = expected energy not supplied; LOLF = loss of load frequency; LOLD = loss of load duration; LOLC = loss of load cost [13], [20], [24] and [25].

\section{Well-being Indices}

The well-being indices are [14]-[16] and [24]: $\mathrm{E}_{\mathrm{H}}=$ expected healthy hours, which is the expected number of hours in a period (e.g. year) the system will stay in healthy states; $\mathrm{E}_{\mathrm{M}}=$ expected marginal hours, which is the expected number of hours in a period (e.g. year) the system will stay in marginal states; $\mathrm{F}_{\mathrm{H}}$ and $\mathrm{F}_{\mathrm{M}}=$ expected frequency associated with healthy and marginal states, respectively; $\mathrm{D}_{\mathrm{H}}$ and $\mathrm{D}_{\mathrm{M}}=$ expected duration of system residing in healthy and marginal states, respectively. The deterministic criterion used to differentiate between healthy and marginal states may be the specified value for the secondary reserve, but the loss of the largest available unit in the system can also be 
used.

\section{Operating Reserve Assessment}

All previous risk indices are based on the following power balance equation:

$$
G-L<0
$$

where $G$ represents the system available generation and $L$ is the total system load. The random variable $G$ depends on the equipment availabilities and on the capacity fluctuations due to, for instance, hydrology and wind variations, etc. The random variable $L$ depends on the short and long-term uncertainties and also on the hourly variations.

In order to assess the performance of the operating reserve, new variables have to be defined as shown in Fig. 2. In this work, the primary (or regulation) and secondary (or spinning) reserves are pre-defined values. Obviously, the spinning reserve amount can always be redefined, in case its associated performance is below a pre-established acceptable value. The tertiary reserve (non-spinning) is composed by those generators that can be synchronized within 1 hour. This reserve is the most relevant in the present study.

The following power balance equation is set to assess the risk indices associated with the operating reserve:

$$
R_{O P E}=R_{S}+R_{T}<\Delta L+\Delta P_{W}+\Delta G
$$

where $\Delta L$ represents the short term load deviation at hour " $t$ "; $\Delta P_{W}$ represents the possible wind power capacity variation at hour " $t$ "; and $\Delta G$ represents the generating capacity variation due to forced outages at hour " $t$ ". From Fig. 2, one can observe an extra amount of capacity at the top of the tertiary reserve. This is due to the discrete effect of unit generating capacities.

Equation (6) describes the risk of changes in the load, wind power capacity and generating outages not being duly covered by the amount of spinning reserve, and also by those generators that can be synchronized within 1 hour. Therefore, the same traditional and wellbeing indices can be evaluated with this risk equation.
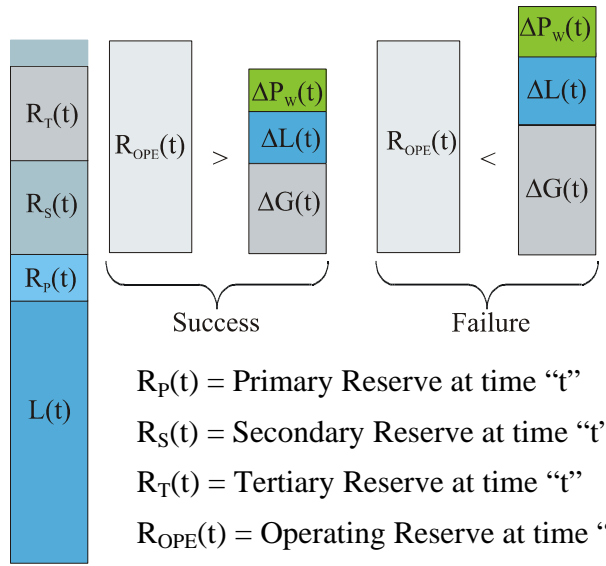

$$
\begin{aligned}
& \mathrm{R}_{\mathrm{P}}(\mathrm{t})=\text { Primary Reserve at time " } \mathrm{t} " \\
& \mathrm{R}_{\mathrm{S}}(\mathrm{t})=\text { Secondary Reserve at time " } \mathrm{t} \text { " } \\
& \mathrm{R}_{\mathrm{T}}(\mathrm{t})=\text { Tertiary Reserve at time " } \mathrm{t} \text { " } \\
& \mathrm{R}_{\mathrm{OPE}}(\mathrm{t})=\text { Operating Reserve at time " } \mathrm{t} \text { " }
\end{aligned}
$$

Figure 2: Operating reserve assessment.
Although there are many reference values for LOLP or LOLE indices (in capacity analysis studies), within the framework of generation planning, there are no reference values for the well-being indices nor for the operating reserve proposed framework.

\section{E. Computational Program Characteristics}

The implementation of the previous models is carried out through a Fortran (calculation mode) and VBasic (user interactive mode) algorithm. The convergence process is tracked through a coefficient of variation specified for the EENS index. Usually, once ensuring the convergence of EENS index, the others will have converged as well. The probability distributions of all, conventional and well-being, reliability indices are also evaluated.

\section{APPLICATION RESUltS}

The proposed algorithm has been tested under several conditions with different systems. A case using the Portuguese and Spanish Generating System (PGS and SGS, respectively) will be discussed as follows. The case will show the results using the PGS and SGS configurations for the year 2005. The idea is to evaluate these configurations to establish certain reliability parameters or standards for the years to come. Further studies will address potential configurations for the years 2010-2020.

\section{A. Portuguese and Spanish Systems}

For the year 2005, the PGS had 1035 units with a total installed capacity of $12.59 \mathrm{GW}$, distributed as follows: $4.38 \mathrm{GW}$ (Hydro); $5.43 \mathrm{GW}$ (Thermal); 0.98 GW (Wind); 0.34 GW (Mini-hydro); and 1.46 GW (Cogeneration). The annual peak load occurred in January and it was approximately $8.53 \mathrm{GW}$. Also, the amount of renewable power in the system is $45 \%$ of the total capacity.

For the year 2005, the SGS had 8150 units with a total installed capacity of $70.2 \mathrm{GW}$, distributed as follows: 15.17 GW (Hydro); 37.1 GW (Thermal); 9.54 GW (Wind); 0.79 GW (Mini-hydro); and 7.6 GW (Cogeneration). The annual peak load occurred in January and it was approximately $43.14 \mathrm{GW}$. Also, the amount of renewable power in the system is $36 \%$ of the total capacity.

In 2005, there were 35 hydro power plants in Portugal and 174 in Spain. In this study, 6 hydrological basins in Portugal and also 6 in Spain were considered, and 16 years of monthly hydrological conditions were used (1990-2005). Figure 3 shows the hydro production variations (Dry, Average and Wet conditions) for Portugal. The driest year was 2005 for Portugal and 1992 for Spain, and the wettest year was 1996 for Portugal and 2003 for Spain. These monthly variations must be duly captured by the MCS-based reliability assessment proposed algorithm. 
In 2005, there were 8 thermal power plants in Portugal and 74 in Spain (not including co-generation). About 655 wind-generating turbines (units) were in the PGS and 6365 in the SGS. Bearing in mind the wind series, Portugal was divided into 7 regions and Spain into 18 regions. In 2005, for the SGS, the day with the highest peak capacity was August $8^{\text {th }}$, and the day with the lowest peak capacity was April $8^{\text {th }}$. Figure 4 shows these two days, and also the average value of the annual wind series. In order to model the deviation $\Delta P_{W}$ in (6), it was assumed a forecasting error by persistence. The error was then estimated by comparing the wind power availability in subsequent hours.

The actual 2005 hourly load curves were used for both PGS and SGS. Uncertainty of the short-term forecasting (i.e. expression $\Delta L$ in Eq. 6) was simulated using a Gaussian distribution. Sensitivity analyses were preliminarily carried out to validate the distribution parameters used in Portugal and Spain.

Several other data involving mini-hydro and cogeneration units, maintenance, etc. have also to be processed. These data are not shown or discussed in this paper due to the lack of space, but they represent relevant information and also sources of variations, which had to be carefully considered.

\section{B. Results}

The proposed MCS algorithm is being tested with several possible configurations of the PGS and SGS. The idea is to determine the required amount of system generating reserve capacity to ensure an adequate power

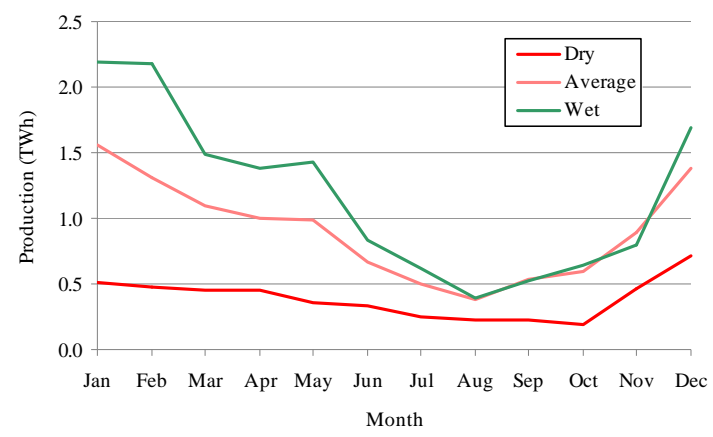

Figure 3: Hydro production, 1990-2005 (Portugal).

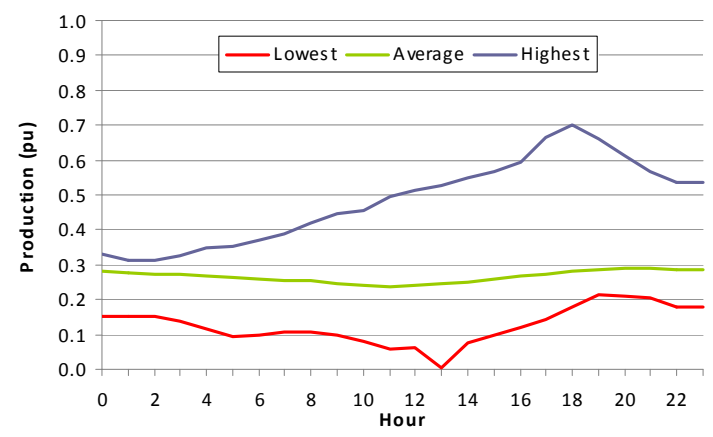

Figure 4: Wind power typical fluctuations, 2005 (Spain). supply, bearing in mind not only the uncertainties from the equipment availabilities, but also the uncertainties due to the renewable power sources capacity variations. This study is being carried out considering a horizon of 20 years (2005-2025). Different scenarios involving not only hydro and wind unfavorable conditions, but also co-generation usage and maintenance strategies are being analyzed.

\section{1) Analysis for the 2005 Configuration}

In order to define reliability standards for the PGS and SGS, the 2005 Configuration was used. Although several operating conditions or cases were tested, only some of them will be discussed. For the Base case, all historical hydrological and wind series were simulated with the 2005 Configuration for both systems. In the $\mathrm{H}^{+}$ case, the wettest hydrological year was considered, and in the $\mathrm{H}^{-}$case, the driest hydrological was simulated. The HWM case considers that driest hydrological condition occurs simultaneously with all observed wind series having their capacities reduced by $50 \%$. Also, the usual amount of power on maintenance was increased by $20 \%$. Certainly, this is a very severe scenario.

Table 1 shows the traditional reliability indices for Portugal. As it can be seen from this table, the PGS configuration (2005) is extremely robust. As it could be expected, the worst condition occurs for "HWM", resulting in indices like: $\mathrm{LOLE}_{\mathrm{CA}}=0.023$ hours/year and the $\mathrm{LOLE}_{\mathrm{OPE}}=0.032$ hour/year. Under these "HWM" conditions, the performance can be considered perfectly acceptable.

Table 2 shows the well-being reliability indices, for Spain. One can provide the following interpretation for this system, if everything goes wrong (i.e. HWM case) with the 2005 configuration. Bearing in mind the capacity analysis, the SGS will stay, in average per year, 8754 hours in healthy states, 3.814 hours in marginal states, and 2.596 hours in risk states. Bearing in mind the operating reserve, the SGS will stay, in average, 8741 hours in a healthy state, 16.20 hours in a marginal state and 2.832 hours in risk states.

These are indeed very low values for that particular stressing scenario.

\begin{tabular}{||l|c|c|c|c||}
\hline Case & $\begin{array}{c}\text { LOLE } \\
\text { (hours) }\end{array}$ & $\begin{array}{c}\text { EENS } \\
\text { (MWh/y) }\end{array}$ & $\begin{array}{c}\text { LOLF } \\
\text { (occ./y) }\end{array}$ & $\begin{array}{c}\text { LOLD } \\
\text { (hours) }\end{array}$ \\
\hline \hline \multicolumn{5}{|c||}{ Capacity Analysis } \\
\hline Base & 0.006 & 0.915 & 0.006 & 1.036 \\
\hline $\mathrm{H}^{+}$ & 0.001 & 0.240 & 0.002 & 0.870 \\
\hline $\mathrm{H}^{-}$ & 0.012 & 1.704 & 0.011 & 1.057 \\
\hline $\mathrm{HWM}$ & 0.023 & 3.784 & 0.021 & 1.076 \\
\hline \hline \multicolumn{5}{|c||}{ Operating Reserve } \\
\hline Base & 0.036 & 3.760 & 0.044 & 0.817 \\
\hline $\mathrm{H}^{+}$ & 0.147 & 12.66 & 0.190 & 0.773 \\
\hline $\mathrm{H}^{-}$ & 0.017 & 2.542 & 0.016 & 1.092 \\
\hline $\mathrm{HWM}$ & 0.032 & 5.304 & 0.031 & 1.026 \\
\hline \hline
\end{tabular}

Table 1: Reliability indices - Portugal 2005. 


\begin{tabular}{||l|c|c|c|c|}
\hline \hline Case & $\begin{array}{c}\mathbf{E}_{\mathbf{H}} \\
\text { (hours) }\end{array}$ & $\begin{array}{c}\mathbf{F}_{\mathbf{H}} \\
\text { (occ./y) }\end{array}$ & $\begin{array}{c}\mathbf{E}_{\mathbf{M}} \\
\text { (hours) }\end{array}$ & $\begin{array}{c}\mathbf{F}_{\mathbf{M}} \\
\text { (occ./y) }\end{array}$ \\
\hline \hline \multicolumn{5}{|c|}{ Capacity Analysis } \\
\hline Base & 8760 & 0.147 & 0.153 & 0.144 \\
\hline $\mathrm{H}^{+}$ & 8760 & 0.000 & 0.001 & 0.000 \\
\hline $\mathrm{H}^{-}$ & 8758 & 1.068 & 1.107 & 0.994 \\
\hline $\mathrm{HWM}$ & 8754 & 3.568 & 3.814 & 3.455 \\
\hline \hline \multicolumn{5}{|c|}{ Operating Reserve } \\
\hline Base & 8756 & 6.914 & 4.188 & 6.909 \\
\hline $\mathrm{H}^{+}$ & 8758 & 1.914 & 1.169 & 1.917 \\
\hline $\mathrm{H}^{-}$ & 8751 & 12.12 & 7.508 & 12.19 \\
\hline $\mathrm{HWM}^{5}$ & 8741 & 24.68 & 16.20 & 24.60 \\
\hline
\end{tabular}

Table 2: Well-being indices - Spain 2005.

It has to be pointed out that the "HWM" scenario impacts more on the Spanish system than on the Portuguese system, since the SGS depended much more on wind sources in 2005: $13.6 \%$ of the installed capacity in Spain, against $7.8 \%$ in Portugal. In conclusion, both systems had very robust composition for the year 2005. Moreover, the proposed simulation algorithm properly captured the performance of both capacity analysis and operating reserves.

The convergence criterion $\beta$ was set to $5 \%$ in all tests for the EENS index, and a maximum of 3000 years were simulated. All simulations were carried out in a PC with 2.8GHz. The CPU time was, in average, 0.4 hours for the PGS and 7 hours for the SGS. These huge $\mathrm{CPU}$ times indicated that convergence was difficult, due to lack of risk states in the simulation, which means that both systems were extremely reliable.

\section{2) Analyses for Future Configurations}

Initially, some sensitivity analyses were carried out with the 2005 configurations, by increasing the peak load of both systems in order to measure the capacity slackness in these configurations. Figure 5 shows the results for the index LOLE associated with the capacity analysis of the SGS (LOLE $\mathrm{CA}_{\mathrm{A}}$ ). Similar sensitivity tests were carried with the LOLE $E_{\mathrm{OPE}}$ indices.

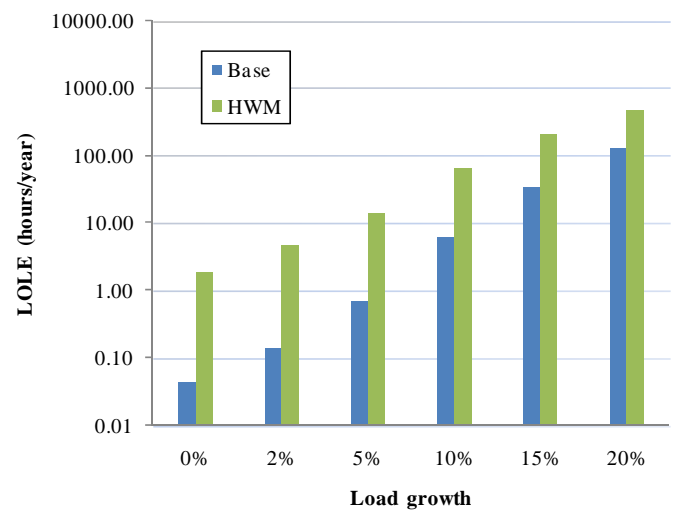

Figure 5: Sensitivity analyses - LOLE $\mathrm{CA}_{\mathrm{C}}$ (hours/year)
In order to assess the risks associated with both capacity analysis and operating reserves in the period 2010-2025, the chronological MCS based algorithm is now being run for both the PGS and SGS.

\section{FINAL REMARKS}

Renewable energy technologies will take a greater share of the electricity generation mix in order to minimize the dependence on oil and the emission of $\mathrm{CO}_{2}$. While contributions from renewable energy sources for electricity production is small, with the exception of hydro, their market penetration is growing at a much faster rate than any other conventional source. More renewable power sources cause, however, an increase in the number of random variables and operation complexities in the system, due to the fluctuating production levels of these sources. Therefore, the determination of the required amount of system capacity (both capacity analysis and operating reserves) to ensure an adequate supply becomes a very important aspect of generating capacity expansion analyses.

The dimensioning of operating reserve, spinning and non-spinning, plays an important role in systems with high penetration levels of renewable sources, mainly those from wind power, due to its natural volatility. Although there are many reference values for LOLE indices related with capacity analysis (e.g. 0.1 day/year [13], 10 hours/year [24]), there are no such standards for well-being indices or for operating reserves.

By testing recently operated generation arrangements, one can provide some preliminary values for the establishment of future standards. However, most generating systems, including the Portuguese and Spanish, have today a smaller amount of fluctuating capacity sources, like wind power, than they will have in the future; even considering that Spain has the second largest wind power capacity installed in the world.

Discussions on innovative criteria (e.g. the system has simultaneously to survive the worst hydrological and wind conditions), operation strategies and assessment tools will be the new insights of generating capacity expansion planning considering renewable power sources for the years to come.

\section{REFERENCES}

[1] EREC - European Renewable Energy Council, “EREC’s Position on the framework directive for renewable energy sources”, 1/10/2007, EREC website (access through: http://www.erec-renewables.org/fileadmin/erec_docs/ Do cuments/ Position Papers/EREC Position Framework Directive.pdf.

[2] Presidency Conclusions of the Brussels European Council (8/9 March 2007), Reference: DOC/07/1, Date: 09/03/2007, Europa website (access through: http://europa.eu/rapid/pressReleasesAction.do?reference $=\mathrm{DOC} / 07 / 1$. 
[3] EU Commission Communication of 10 January 2007: "Renewable energy road map - renewable energies in the 21st century: building a more sustainable future", Europa website (through: http://europa.eu/scadplus/leg/en/lvb/ 127065.htm).

[4] S. Rahman, "Green Power: What is it and where can we find it?”, IEEE Power and Energy Magazine, Vol. 1, No. 1, pp. 30-37, Jan./Feb. 2003.

[5] N. Hatziargyriou and A. Zervos, "Wind power development in Europe", Proceedings of the IEEE, Vol. 89, No. 12, pp. 1765-1782, Dec. 2001.

[6] R. Ramakumar, J.G. Slootweg, L. Wozniak, "Guest Editorial: Introduction to the special issue on wind power", IEEE Trans. on Energy Conversion, Vol. 22, No. 1, pp. 1-3, Mar. 2007.

[7] L. Söder, L. Hofmann, A. Orths, H. Holttinen, Y. Wan and A. Tuohy, "Experience from wind integration in some high penetration areas”, IEEE Trans. on Energy Conversion, Vol. 22, No. 1, pp. 4-12, Mar. 2007.

[8] B.C. Ummels, M. Gibescu, E. Pelgrum, W.L. Kling and A.J. Brand, "Impacts of wind power on thermal generation unit commitment and dispatch", IEEE Trans. on Energy Conv., Vol. 22, No. 1, pp. 44-51, Mar. 2007.

[9] G. Strbac, A. Shakoor, M. Black, D. Pudjianto and T. Bopp, "Impact of wind generation on the operation and development of the UK electricity systems", Electric Power Systems Research, Vol. 77, No. 9, pp. 1214-1227, July 2007.

[10] M. O’Malley and J.J. Sanches-Gasca, “Guest Editorial: Special section on wind energy", IEEE Trans. on Power Systems, Vol. 22, No. 3, pp. 899, Aug. 2007.

[11] R.G. Almeida and J.A. Pecas Lopes, "Participation of Doubly Fed Induction Wind Generators in System Frequency Regulation”, IEEE Trans. on Power Systems, Vol. 22, No. 3, pp. 944-950, Aug. 2007.

[12] P. Sørensen, N.A. Cutululis, A. Vigueras-Rodriguez, L.E. Jensen, J. Hjerrild, M.H. Donovan and H. Madsen, "Power fluctuations from large wind farms", IEEE Trans. on Power Systems, Vol. 22, No. 3, pp. 958-965, Aug. 2007.

[13] R. Billinton and R.N. Allan, "Reliability Evaluation of Power Systems”, Plenum Press, New York, 1996.

[14] R. Billinton and M. Fotuhi-Firuzabad, "A basic framework for generating system operating health analysis", IEEE Trans. on Power Systems, Vol.9, No. 3, pp.1610-1617, Aug. 1994.
[15] R. Billinton and R. Karki, "Application of Monte Carlo simulation to generating system well-being analysis", IEEE Trans. on PWRS, Vol. 14, No. 3, pp. 1172-1177, Aug. 1999.

[16] A.M. Leite da Silva, L.C. Resende, L.A.F. Manso and R. Billinton, "Well-being analysis for composite generation and transmission systems", IEEE Trans. on Power Systems, vol. 19, no. 4, pp. 1763-1770, Nov. 2004.

[17] X. Wang, H. Dai and R.J. Thomas, "Reliability modeling of large wind farms and electric utility interface systems", IEEE Trans. on PAS, Vol. 103, No. 3, pp. 569575, Mar. 1984.

[18] C. Singh and A.L. Gonzalez, "Reliability modeling of generation systems including unconventional energy sources", IEEE Trans. on PAS, Vol. 104, No. 5, pp. 1049-1056, May 1985.

[19] G. Desrochers and M. Blanchard, "A Monte Carlo simulation for the economical assessment of the contribution of wind energy to power systems", IEEE Trans. on Energy Conv., Vol. 1, No.4, pp. 50-56, 1986.

[20] A.M. Leite da Silva, A.C.G. Melo and S.H.F. Cunha, "Frequency and duration method for reliability evaluation of large-scale hydrothermal generating systems", IEE Proc.-C, Vol.138, No.1, pp.94-102, Jan. 1991.

[21] R. Billinton and A.A. Chowdhury, "Incorporating of wind energy conversion systems in conventional generating capacity adequacy assessment", IEE Proc.-C, Vol. 139, No. 1, pp. 45-56, Jan. 1992.

[22] R. Billinton, H. Chen and R. Ghajar, "A sequential simulation technique for adequacy evaluation of generating systems including wind energy", IEEE Trans. on Energy Conv., Vol. 11, No. 4, pp. 728-734, 1996.

[23] F.C. Sayas and R.N. Allan, "Generation availability assessment of wind farms", IEE Proc.-C, Vol. 143, No. 5, pp. 507-518, Sept. 1996.

[24] A.M. Leite da Silva, L.A.F. Manso, W.S. Sales, L.C. Resende, M.J.Q. Aguiar, M.A. Matos, J.A. Peças Lopes and V. Miranda, "Application of Monte Carlo Simulation to Generating System Well-Being Analysis Considering Renewable Sources, European Transactions on Electrical Power, Vol. 17, No. 4, pp. 387-400, Jul.-Aug. 2007.

[25] A.M. Leite da Silva, L.A.F. Manso, J.C.O. Mello, R. Billinton, "Pseudo-chronological simulation for composite reliability analysis with time varying loads", IEEE Trans. on Power Systems, Vol. 15, No. 1, pp. 7380, Fev. 2000 